Special Issue of the 8th International Advances in Applied Physics and Materials Science Congress (APMAS 2018)

\title{
Determination of Optimal Conditions for Production of Highly Porous Carbon by Chemical Activation Method
}

\author{
Y.E. ŞIMŞEK* \\ Bilecik Şeyh Edebali University, Chemical Engineering Department, Bilecik, Turkey
}

\begin{abstract}
Activated carbon is a complex and crude form of graphite. Compared to graphite, activated carbon exhibits an unusual imperfect structure that is tremendously porous ranging from nanopore to milipore sizes. Its graphitelike structure yields the carbon its very large surface area which takes a great advantage to adsorb a wide range of substances. Although the production of activated carbon from the raw materials such as coal and coal tar pitch prevails, its production from agricultural wastes is possible. In this study the canola straw is considered as a potential activated carbon source. The examined samples were obtained by chemical activation. New kind of carbons were characterized by elemental analysis, the Brunauer-Emmett-Teller (BET) surface area, scanning electron microscopy (SEM) images, and the Fourier transform infrared spectroscopy (FTIR). Besides, the effect of experimental parameters on chemical and pore properties of the activated carbon materials was modeled and optimized.
\end{abstract}

DOI: 10.12693/APhysPolA.135.1036

PACS/topics: agricultural waste, activated carbon, $\mathrm{KOH}$ activation, characterization, optimization

\section{Introduction}

Activated carbons are amorphous materials with high degree of porosity and well-developed external surface area. They boast their tremendous industrial applications such as elimination of toxic chemicals, drinking water purification, municipal waste and industrial effluents treatment, catalysis and catalyzer support, energy storage, super capacitor electrodes, precious metal recovery and cosmetics [1-3]. The adsorptive properties of activated carbons are strongly influenced by many factors such as their porosity and textural characteristics, surface functional groups, reactivity and the method whereby activated carbons are produced.

Activated carbons are largely produced from fossilbased resources, but their depletion in the near future and their harmful and irreversible effects on the natural environement are one of the most serious problems humankind has been confronted with throughout history [4]. Hence the attention to the production of activated carbon from renewable and eco-friendly sources has been directed towards biomass. Considered as biomass feedstock agricultural waste and residues comprise high carbon content which render them excellent candidate precursors for the production of activated carbon [5]. The physical and chemical activation methods are employed to produce activated carbon. The advantages of the former over the latter are relatively lower carbonization temperatures, shorter carbonization times, higher activated carbon yields, high surface area (up to $3000 \mathrm{~m}^{2} / \mathrm{g}$ ) and a well-developed micropore structure. In the chemical activation method, as the starting raw material, the biomass

\footnotetext{
*e-mail: yunusemre.simsek@bilecik.edu.tr
}

is impregnated with a chemical agent and the treated material is heated up to $400-800^{\circ} \mathrm{C}$ for carbonization in an inert nitrogen gas atmosphere [3].

In this study activated carbons were produced from Brassica Napus (canola straw) by chemical activation method with potassium hydroxide. The effects of carbonization temperature and impregnation ratio on surface textural properties, chemical composition and yield of the activated carbon samples produced were thoroughly investigated. Furthermore, the produced activated carbons were characterized by BET, the Fourier transform infrared spectroscopy (FTIR), scanning electron microscopy and elemental analyzer.

\section{Experimental procedure}

$20 \mathrm{~g}$ of the dried and ground material with particle size of $0.224 \mathrm{~mm}-0.112 \mathrm{~mm}$ was impregnated with a $300 \mathrm{~mL}$ of $\mathrm{KOH}$ solution at different impregnation ratios (1:1, $1: 2,1: 3$, and 1:4) separately. The mixtures were put in a laboratory scale hot water bath and kept at $85^{\circ} \mathrm{C}$ for $6 \mathrm{~h}$ with vigorous stirring to ensure the penetration of the chemical agent into the interior of the samples. After this treatment, the mixtures were paper-filtered and the resulting acid-impregnated solids were dried at $105{ }^{\circ} \mathrm{C}$ for $24 \mathrm{~h}$ to remove moisture completely. $5 \mathrm{~g}$ of the impregnated samples was placed into a tubular reactor and carbonized at different temperatures $\left(400,500\right.$, and $\left.600{ }^{\circ} \mathrm{C}\right)$ at a heating rate of $10^{\circ} \mathrm{C} / \mathrm{min}$ under $150 \mathrm{~cm}^{3} / \mathrm{min}$ of nitrogen gas flow for $2 \mathrm{~h}$. The produced materials were washed with hot distilled water. They were designated as IT00 where I refers to impregnation ratio and T00 to temperature.

\section{Results and discussion}

Detailed SEM and elemental analysis were used for the enlightenment of textural and chemical properties 
of the activated carbon samples. Table I shows surface textural properties and elemental analysis, depending on the impregnation ratios and carbonization temperatures. Chemical activation led to a decrease in a $\mathrm{H} / \mathrm{C}$ ratio from 1.610 in the raw material to 0.261 in AC4600. Likewise, the $\mathrm{O} / \mathrm{C}$ ratio also decreased from 0.730 in the raw material to 0.022 in AC4600. As expected, activated carbon has higher content of carbon and lower content of oxygen and hydrogen. A similar result has been reported by Yorgun and Yıldız [3]. It is clear from Table $\mathrm{I}$ that $\mathrm{H} / \mathrm{C}$ and $\mathrm{O} / \mathrm{C}$ ratios decrease with the increase of impregnation ratio and temperature. The yield can be defined as the ratio of the weight of the activated carbon after carbonization to the weight of the raw material. The carbonization temperature and impregnation ratio had a clear effect on the yield of activated carbon. As the activation temperature increases from
$400{ }^{\circ} \mathrm{C}$ to $600^{\circ} \mathrm{C}$, the activated carbon yield decreases from $52.11 \%$ to $17.68 \%$. This decrease is the direct result of the loss of volatile materials with increasing carbonization temperature. Also, at each carbonization temperature, the yield decreases with increasing impregnation ratio. This is because potassium hydroxide reacts with the carbon char and volatile matters are removed rapidly outside the particle surface during the chemical activation. The decomposition and gasification of the chemical agent-loaded raw material came to the fore, causing an increase in the weight loss and carbon yield $[3,6]$. Both activation temperature and impregnation ratio affects all the textural properties of the activated carbons, presented in Table I. These properties increased with increasing temperature and impregnation ratio with the exception of AC3500 and AC4500.

The textural and chemical properties of the activated carbons.

TABLE I

\begin{tabular}{c|c|c|c|c|c|c|c|c|c|c|c}
\hline \hline Label & $\begin{array}{c}S_{\text {BET }} \\
{\left[\mathrm{m}^{2} / \mathrm{g}\right]}\end{array}$ & $\begin{array}{c}S_{\text {mic }} \\
{\left[\mathrm{m}^{2} / \mathrm{g}\right]}\end{array}$ & $\begin{array}{c}S_{\text {mes }} \\
{\left[\mathrm{m}^{2} / \mathrm{g}\right]}\end{array}$ & $\begin{array}{c}V_{\text {tot }} \\
{\left[\mathrm{cm}^{3} / \mathrm{g}\right]}\end{array}$ & $\begin{array}{c}V_{\text {mic }} \\
{\left[\mathrm{cm}^{3} / \mathrm{g}\right]}\end{array}$ & $\begin{array}{c}V_{\text {mes }} \\
{\left[\mathrm{cm}^{3} / \mathrm{g}\right]}\end{array}$ & $\begin{array}{c}d_{\text {av }} \\
{[\AA]}\end{array}$ & $\begin{array}{c}\mathrm{H} / \mathrm{C} \\
{[\mathrm{molar} \text { ratio }]}\end{array}$ & $\begin{array}{c}\mathrm{O} / \mathrm{C} \\
{[\%]}\end{array}$ & $\begin{array}{c}Y \\
{[\%}\end{array}$ \\
\hline raw & 1.1133 & 0.000110 & 1.11319 & 0.00908 & 0.00012 & 0.00896 & 191.42 & 1.610 & 0.730 & - \\
\hline AC1400 & 394.27 & 295.72 & 98.55 & 0.19984 & 0.13589 & 0.06395 & 20.79 & 0.616 & 0.503 & 52.11 \\
AC1500 & 572.19 & 474.76 & 97.43 & 0.22219 & 0.14157 & 0.08062 & 20.36 & 0.423 & 0.024 & 44.38 \\
AC1600 & 902.44 & 730.97 & 171.47 & 0.414 .27 & 0.30242 & 0.11185 & 20.32 & 0.417 & 0.029 & 29.17 \\
AC2400 & 423.49 & 317.25 & 106.24 & 0.20519 & 0.14183 & 0.06336 & 20.72 & 0.609 & 0.025 & 60.82 \\
AC2500 & 674.11 & 539.59 & 134.52 & 0.27624 & 0.19657 & 0.07967 & 20.44 & 0.431 & 0.024 & 45.09 \\
AC2600 & 926.89 & 746.11 & 180.78 & 0.40017 & 0.30181 & 0.09836 & 19.64 & 0.422 & 0.032 & 21.33 \\
AC3400 & 486.92 & 351.64 & 135.28 & 0.22472 & 0.16279 & 0.06193 & 20.68 & 0.409 & 0.026 & 63.44 \\
AC3500 & 1012.72 & 850.69 & 162.03 & 0.49815 & 0.40415 & 0.09400 & 19.86 & 0.392 & 0.026 & 50.72 \\
AC3600 & 942.14 & 768.72 & 173.42 & 0.43286 & 0.10198 & 0.10198 & 19.66 & 0.294 & 0.024 & 19.40 \\
AC4400 & 434.49 & 301.11 & 133.38 & 0.21982 & 0.14539 & 0.07443 & 20.64 & 0.303 & 0.023 & 62.85 \\
AC4500 & 911.82 & 752.89 & 158.93 & 0.48726 & 0.35297 & 0.13429 & 19.61 & 0.297 & 0.023 & 48.62 \\
AC4600 & 805.62 & 708.49 & 97.13 & 0.39827 & 0.29440 & 0.10387 & 19.61 & 0.261 & 0.022 & 17.68 \\
\hline
\end{tabular}

$S_{\mathrm{BET}}$ : BET surface area; $S_{\text {mic }}$ : micropore surface area; $S_{\text {mes }}$ : mesopore surface area; $V_{\text {tot }}$ : total pore volume; $V_{\text {mic }}:$ micropore volume; $V_{\text {mes }}$ : mesopore volume, $d_{\mathrm{av}}$ : average pore size, and $Y$ : yield of activated carbon produced

The rise in temperature from $500^{\circ} \mathrm{C}$ to $600{ }^{\circ} \mathrm{C}$ may have induced shrinkage in the carbon structure, leading to a decline in the surface areas and pore volumes. The surface area, micropore and mesopore surface area, total pore volume and micropore and mesopore volume ranged from 394.27 to $1012.72 \mathrm{~m}^{2} / \mathrm{g}$, from $98.55 \mathrm{~m}^{2} / \mathrm{g}$ to 180.78 $\mathrm{m}^{2} / \mathrm{g}$, from 0.19984 to $0.49815 \mathrm{~cm}^{3} / \mathrm{g}$, from 0.13589 to $0.14183 \mathrm{~cm}^{3} / \mathrm{g}$, from 0.06193 to $0.13429 \mathrm{~cm}^{3} / \mathrm{g}$, respectively. The effect of carbonization temperature and impregnation ratio on these properties is more notable in AC3500 i.e. in the impregnation ratio of 3:1 at $500{ }^{\circ} \mathrm{C}$. The maximum surface and pore volumes were obtained at these conditions. The average pore size of the activated carbon kept almost constant $(\approx 20 \AA)$, which definitely indicates that the all the produced carbons have mainly microporous structure. It is known that activated carbons have surface functional groups. The characteristics of these groups depend strongly on raw material and activation methods.

The FTIR spectrum of the activated carbon (AC3500) obtained at the optimum conditions of temperature $\left(500^{\circ} \mathrm{C}\right)$ and impregnation $(3: 1)$ is shown in Fig. 1a. The broad peak at $3332 \mathrm{~cm}^{-1}$ indicates the presence of $\mathrm{O}-\mathrm{H}$ stretching vibrations. The peak at $2922 \mathrm{~cm}^{-1}$ can be attributed to the aliphatic $\mathrm{C}-\mathrm{H}$ stretching vibrations. The weak band at $2300 \mathrm{~cm}^{-1}$ may be ascribed to the oxygen-bonded $\mathrm{C}=\mathrm{O}$ groups from carboxylic acid. The peak at $1595 \mathrm{~cm}^{-1}$ shows unsaturated $\mathrm{C}-\mathrm{C}$ stretching groups. The absorbance peak at $1222 \mathrm{~cm}^{-1}$ is $\mathrm{C}-\mathrm{O}$ stretching vibrations in ester, ether, and phenol groups. The band at around $879 \mathrm{~cm}^{-1}$ can be due to $\mathrm{C}-\mathrm{H}$ out of plane bending vibration in an aromatic ring $[3,7]$. 

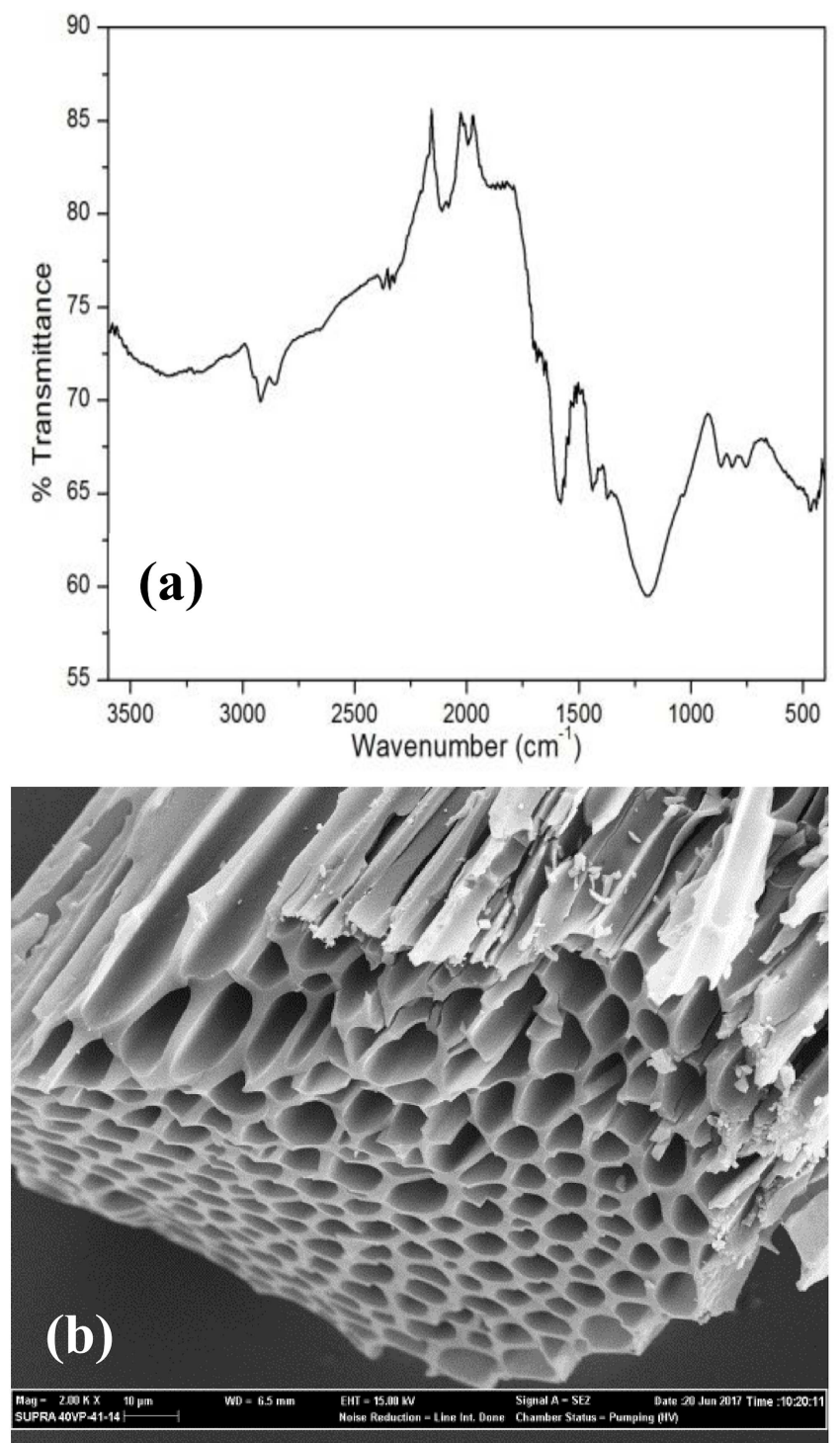

Fig. 1. (a) FTIR spectrum and (b) SEM micrograph of the activated carbon (AC3500) at the optimum conditions.
Scanning electron micrograph of the AC3500 produced at the optimum conditions is presented in Fig. 1b. Figure $1 \mathrm{~b}$ clearly shows the activated carbon surface consists mainly of well-developed pores with a tunnel shape and honeycomb-like structure.

\section{Conclusion}

The employment of an ample, versatile, eco-friendly and cost-effective to produce activated carbon is the obvious choice for the production of inexpensive activated carbon. In this study Brassica Napus which was considered to meet the aforementioned requirements was selected for the production of activated carbon. The effect of carbonization temperatures and impregnation ratios on the activated carbon yield, chemical and textural properties was investigated. The optimal conditions were found to be an impregnation ratio of 3:1 and carbonization temperature of $500^{\circ} \mathrm{C}$. The values of the surface $\left(S_{\mathrm{BET}}\right.$ and $\left.S_{\mathrm{mic}}\right)$ and pore volumes $\left(V_{\text {tot }}\right.$ and $\left.V_{\text {mic }}\right)$ are $1012.72,850.69 \mathrm{~m}^{2} / \mathrm{g}, 0.49815$, and $0.40415 \mathrm{~m}^{3} / \mathrm{g}$, respectively. It turned out Brassica Napus is an appropriate starting raw material for activated carbon production.

\section{References}

[1] A. Malaika, P. Rechnia-Goracy, M. Kot, M. Kozłowski, Catal. Today 301266 (2018).

[2] N. Bader, A. Ouederni, J. Energy Storage 13, 268 (2017).

[3] S. Yorgun, D. Ylldız, J. Taiwan Inst Chem Eng 53, $122(2015)$.

[4] N.A. Rashidi, S. Yusup, J. Clean. Prod. 168, 474 (2017).

[5] M. Danish, T. Ahmad, Ren. Sust. Energ Rev. 87, 1 (2018).

[6] P. Patnukao, P. Pavasant, Bioresour. Technol. 99, 8540 (2008).

[7] Ş. Karadirek, H. Okkay, J. Ind. Eng.Chem. 63, 340 (2018). 